\title{
Vagus nerve stimulator in patients with epilepsy: indications and recommendations for use
}

\author{
Estimulação do nervo vago em pacientes com epilepsia: indicações e recomendações de uso \\ Vera C Terra ${ }^{1,2}$, Ricardo Amorim¹, Carlos Silvado 1,2, Andrea Julião de Oliveira ${ }^{1}$, Carmen Lisa Jorge', \\ Eduardo Faveret', Paulo Ragazzo', Luciano De Paola ${ }^{1,2}$
}

\begin{abstract}
Epilepsy comprises a set of neurologic and systemic disorders characterized by recurrent spontaneous seizures, and is the most frequent chronic neurologic disorder. In patients with medically refractory epilepsy, therapeutic options are limited to ablative brain surgery, trials of experimental antiepileptic drugs, or palliative surgery. Vagal nerve stimulation is an available palliative procedure of which the mechanism of action is not understood, but with established efficacy for medically refractory epilepsy and low incidence of side-effects. In this paper we discuss the recommendations for VNS use as suggested by the Brazilian League of Epilepsy and the Scientific Department of Epilepsy of the Brazilian Academy of Neurology Committee of Neuromodulation.
\end{abstract}

Keywords: epilepsy, palliative procedures, vagus nerve stimulation.

\section{RESUMO}

As epilepsias compreendem uma família de doenças neurológicas e sistêmicas que se apresentam com crises espontâneas repetitivas, sendo a doença neurológica crônica mais frequente. Em pacientes com epilepsias refratárias ao tratamento medicamentoso, as opções terapêuticas são restritas a cirurgia ablativa, estudos experimentais com novas drogas antiepilépticas ou cirurgias paliativas. A estimulação do nervo vago (VNS) é um procedimento paliativo disponível, cujo mecanismo de ação é ainda desconhecido, mas com eficácia estabelecida em pacientes com epilepsias refratárias ao tratamento medicamentoso, apresentando baixos índices de efeitos colaterais. Neste artigo apresentamos o posicionamento do Comitê de Neuromodulação da Liga Brasileira de Epilepsia e do Departamento Científico de Epilepsia da Academia Brasileira de Neurologia sobre as indicações de uso do VNS

Palavras-chave: epilepsia, procedimentos paliativos, estimulação do nervo vago.

Epilepsy comprises a set of neurologic and systemic disorders characterized by recurrent spontaneous seizures, and is the most frequent chronic neurologic disorder, with an estimated frequency of 4-10 in 1000 individuals per year ${ }^{1}$. In many cases, patients with epilepsy can maintain a normal and unrestricted life because antiepileptic drugs (AEDs) - the mainstay for epilepsy treatment - can provide satisfactory control or total relief of seizures. Nevertheless, despite considerable progress in drug and epilepsy research and carefully optimized AED treatment, approximately 35\% of all epilepsy patients experience recurrent non-provoked spontaneous seizures ${ }^{2}$.

Patients with epilepsy may have severe impairment due to repetitive or prolonged seizures, with progressively impaired cognitive function, brain damage, and other neuropsychiatric deficits commonly occurring in pharmacoresistant or untreated patients ${ }^{1}$. In patients with medically refractory epilepsy, therapeutic options are limited to ablative brain surgery, trials of experimental AEDs, or palliative surgery ${ }^{3}$. All patients with failure in treatment with two or more appropriated AEDs, given in adequate dosage, may be considered in this group ${ }^{4}$. In such cases, patients should be referred to centers specializing in epilepsy treatment, investigation and surgery. Brain resective surgery, when possible, usually gives the best chance for patients to be seizure free, but curative epilepsy surgery can only be performed in a subgroup of medically refractory patients in whom the epileptogenic focus can be localized and does not overlap with eloquent brain areas. In the other patients (with bilateral or multiple epileptogenic foci, with epilepsy onset in eloquent

${ }^{1}$ Comissão de Neuromodulação da Liga Brasileira de Epilepsia, São Paulo SP, Brasil;

${ }^{2}$ Departamento Científico de Epilepsia da Academia Brasileira de Neurologia, São Paulo SP, Brasil.

Correspondence: Vera Cristina Terra; Hospital de Clınicas UFPR; Rua General Carneiro 181 / 3o andar; 80060-900 Curitiba PR - Brasil; E-mail: v.c.terra@gmail.com

Conflict of interest: There is no conflict of interest to declare. No finantial support.

Received 02 April 2013; Received in final form 30 April 2013; Accepted 05 May 2013. 
areas, or with no identifiable epileptogenic focus), palliative treatments such as a ketogenic diet, corpus callosotomy and vagal nerve stimulation can be offered if they suffer from disabling seizures ${ }^{5}$.

Even when these palliative treatments do not lead to complete control of seizures, a significant reduction of number and severity of seizures may be helpful for both patients and parents, reducing the risk of sudden unexpected death in epilepsy (SUDEP), status epilepticus, severe traumas, hospitalization and emergency department visits, reducing total healthcare costs and increasing the independence and quality of life ${ }^{6}$.

Corpus callosotomy dates from 1940 and its application and effectiveness in drop attacks and secondarily generalized tonic-clonic seizures has general acceptance for patients with intractable, non-resectable refractory epilepsy ${ }^{7}$. However, controversy continues over the extent of corpus callosum resection, the risk of complication and patient selection. In large series, callosotomy was reported to render seizure-free outcome in $7.6 \%$ of patients, most of whom presented with drop-attack seizures ${ }^{7}$. Operative complications reported in earlier studies, such as hemiparesis, mesial hemispheric infarcts and hemispheric edema, were less frequent in recent series and most adverse events related to corpus callosotomy are transient and include neurologic deficits, mutism, apraxia, hemorrhage and postoperative infection ${ }^{8}$. Permanent focal neurologic deficits are rare.

Another available palliative procedure is neuromodulation. Neuromodulation strategies have been proposed to treat a variety of neurologic disorders, including medication-resistant epilepsy. Electrical stimulation of both central and peripheral nervous systems has emerged as a possible alternative for patients who are not deemed to be good candidates for resective procedures ${ }^{9,10}$. The only neuromodulation procedure for treatment of epilepsy approved in Brazil is vagus nerve stimulation (VNS). Other forms of neuromodulation, such as facial or trigeminal nerve stimulation and deep brain stimulation, can only be used at an experimental level.

\section{VAGUS NERVE STIMULATION}

The vagus nerve is the largest cranial nerve and comprises large myelinated A fibers, small myelinated B fibers, and unmyelinated C fibers. About $80-90 \%$ of its fibers are afferent, encoding predominantly visceral sensory non-pain information, and emerge from, or converge to, four nuclei: the dorsal nucleus of the vagus nerve, the nucleus ambiguus, the solitary tract nucleus and the spinal trigeminal nucleus ${ }^{11}$. Assymetric heart innervations play an important role: the right vagus nerve is intimately associated with atriums and the left nerve with ventricles, and owing to the fact that the vagus innervation of the ventricles is less dense than that of the atriums, left VNS is less associated with arrhythmias ${ }^{11}$.
Despite many studies, the exact mechanism by which VNS reduces seizure frequency is unknown, and many theories are have been proposed. It is believed that VNS may modulate electrical stimuli to the nucleus tractus solitarius and the brainstem reticular formation ${ }^{12}$. In this way, VNS may interrupt the synchronous electrical activity characteristic of seizures ${ }^{13,14}$. Earlier research has attempted to characterize the mechanism of action of VNS by using EEGs, evoked potentials, cerebrospinal fluid (CSF) neurochemistry and functional imaging. CSF studies have shown a significant increase in gamma-aminobutyric acid (GABA) after 3-4 months of VNS treatment, but no significant decrease in glutamate, aspartate or 5-hydroxyindoleacetic acid (5-HIAA) levels after 3 to 9 months of VNS treatment. Non-responders had the greatest effect on neurotransmitter levels ${ }^{15}$. Long-term VNS had no effect on interictal EEG background or epileptiform activity, and no effect on visual or auditory evoked potentials. One report showed an increase in the N13-N20 interpeak interval with prolonged $\mathrm{VNS}^{16}$.

Although the VNS mechanism of action is essentially unknown, a number of studies using functional imaging techniques, such as single-photon emission computed tomography (SPECT) and positron emission tomography (PET), have demonstrated widespread changes in blood flow and metabolism in several cortical and subcortical regions during short-term VNS use ${ }^{17}$. These widespread changes in blood flow and metabolism in various cerebral structures have formed the foundation of hypotheses that attempt to explain the VNS effect ${ }^{18}$.

Many pre-clinical studies have been performed on dogs, monkeys and rats to demonstrate that VNS was effective in the prevention, or reduction in the intensity and duration, of seizures ${ }^{19-24}$. Following this research, five studies (E1-E5) were performed in humans to evaluate the efficacy and safety of VNS for clinical use. The first studies (E1 and E2) were blind, 2-year pilot studies of 14 patients with focal epilepsy. The third study (E3) was a randomized, double-blind and casecontrol study of 114 patients with focal epilepsy, followed for 2 years. The fourth study (E4) was a comparative use study in 124 patients with all type of seizures. The final study (E5) was a randomized, double blind, case-control study of 199 patients with focal epilepsy in 1995-1996. In all studies, 454 patients were given VNS implants, and 440 patients yielded assessable data. An approximate $50 \%$ seizure reduction post implantation occurred in $36.8 \%$ of patients at 1 year, in $43.2 \%$ at 2 years, and in $42.7 \%$ at 3 years. Median seizure reductions compared with baseline were $35 \%$ at 1 year, $44.3 \%$ at 2 years, and $44.1 \%$ at 3 years ${ }^{25,26}$.

As a consequence of these studies, prolonged, intermittent electrical stimulation of the left cervical portion of the vagus nerve was established as efficacious therapy of medically refractory epilepsy. Subsequent clinical investigations reported evidence of incremental seizure reductions over 
months of ongoing vagus nerve stimulation and VNS efficacy in generalized epilepsy ${ }^{27}$. In addition to decreasing seizure frequency, an improvement in mood was witnessed in patients who had received VNS, even in those with little or no change in seizure frequency ${ }^{28}$. Clinical studies showed a $31 \%$ response after 3 months of VNS therapy, with further improvements at 6 and 12 months $^{29}$.

Most post-implantation adverse effects are relatively minor, and the most common effects at 1 year encompass hoarseness $(28 \%)$ and paresthesia (12\%), at 2 years hoarseness $(19.8 \%)$ and headache $(4.5 \%)$, and at 3 years shortness of breath (3.2\%). These adverse events change over time, and have a tendency to diminish or disappear ${ }^{30}$.

VNS therapy is considered a palliative treatment in patients with confirmed drug-resistant epilepsy, without indication of resective brain epilepsy surgery, for all types of seizures in adults and children ${ }^{31-34}$ and has been used to treat pharmacoresistant epilepsy in Europe since 1994. In USA, the Food and Drug Administration (FDA) approved VNS in July 1997 for use as an adjunctive therapy for adults or adolescents older than 12 years with medically refractory partial onset seizures ${ }^{35}$. A Brazilian study evaluating 36 patients demonstrated at least $50 \%$ seizure reduction in $61.3 \%$ of implanted patients, concluding that VNS should be considered as a treatment option even in countries with limited resources ${ }^{36}$.

There is insufficient confirmation about the efficacy and safety of VNS implantation in patients with idiopathic generalized epilepsy (IGE) or progressive epilepsy. Some authors have suggested that at least some patients with IGE ${ }^{37,38}$ or progressive forms of epilepsy ${ }^{39}$ can benefit from this procedure.

In Brazil, VNS is approved by ANVISA ('Agência Nacional de Vigilância Sanitária, or National Health Surveillance Agency) for use in patients who have been diagnosed with refractory, focal or generalized epilepsy for 2 or more years. However, patients' suitability for VNS implantation needs further discussion. In a recent meta-analysis ${ }^{40}$, VNS was considered effective and relatively safe as adjunctive therapy in patients with medically refractory epilepsy not suited to brain resective surgery or in patients who failed to become seizure free after epilepsy surgery. In this study, the authors found that children experienced a slightly better outcome than adults. Also, patients with generalized epilepsy benefited more than those with partial seizures. In terms of epilepsy etiology, the best outcomes were observed in patients with post-traumatic epilepsy and with tuberous sclerosis ${ }^{40}$.

\section{RECOMMENDATIONS FOR VNS USE}

Considering all these published data, the Brazilian League of Epilepsy Committee of Neuromodulation (Brazilian Chapter of the International League Against Epilepsy) and the Scientific Department of Epilepsy of the Brazilian Academy of Neurology (Brazilian Chapter of the World Federation of Neurology) suggest that VNS should be considered for patients with refractory epilepsy at any age in the following cases:

1. Patients who have failed to become seizure free following adequate trials (whether as monotherapies or in combination) of two tolerated and appropriately chosen and used first-generation AEDs (phenobarbital, phenytoin, carbamazepine, valproic acid) ${ }^{4}$ plus another trial with at least one second- or third-generation AED (oxcarbazepine, lamotrigine, topiramate, vigabatrin, clobazam, levetiracetam);

2. Patients who have been previously evaluated at specialized secondary- or tertiary-level epilepsy centers with the aim of diagnosis confirmation and exclusion of epilepsy surgery as a treatment option (owing to unacceptable neurologic deficits, high surgery risk or refusal of the patient to undergo epilepsy surgery);

3. Patients with indication for invasive evaluation (i.e. intracranial electrodes should first be inserted and, if epilepsy surgery is not recommended, they should then be considered for VNS implantation);

4. Patients with ultra-refractory status epilepticus;

5. Patients with idiopathic generalized epilepsy or progressive epilepsy who meet the abovementioned requirements should receive an in-depth consultation, and should only be considered for implantation with the agreement of at least two secondary- or tertiary-level epilepsy center teams.

\section{RECOMMENDATIONS FOR VNS MANAGEMENT}

VNS stimulation parameters should be adjusted individually for each patient. However, the treatment of certain variables remains the same for all patients. The VNS generator is usually turned on 1-2 weeks after implantation, with a progressive increase in output current. A faster current increment may be attempted if the patient tolerates therapeutic levels in a single visit ${ }^{41}$. Typical values for a satisfactory response should be 1-2 milliamps, but values between 0.25 and 3.5 milliamps are possible. Other values that may be adjusted at follow up are signal frequency, pulse width, signal on-time and signal off-time. If seizure frequency reduction is not satisfactory at 1.5 milliamps, signal on-time may be increased or signal off-time decreased. In cases of intolerable or permanent side-effects, pulse width and current output may be temporarily reduced. Adjustments should be made at an interval of at least one week until stimulation reaches 0.75 or 1 milliamp, and then at intervals of 1 month for the first six months, followed by 3-month intervals.

Special care should be given to patients requiring longterm follow-up because the generator's battery usually needs 
to be replaced after 5-10 years, depending on the intensity of the stimulation used. In the new models it is possible, when testing the operation of the generator, to evaluate the battery level and thereby monitor patients more closely. If the generator battery runs out of charge, the device is switched off and the patient may experience an increase in seizure frequency, so it must be replaced as soon as possible.

In conclusion, the use of implanted devices has become an interesting and potentially useful tool in the therapeutic strategy for patients with epilepsy. VNS belongs to this category and, considering that it has already been approved for clinical use since years ago, one would expect that systematic and objective indication for implantation should be available. In practical terms, this is not the case. At first glance, VNS is a technology that represents an economic challenge for most healthcare systems. However, the investment could be justified in terms of the potential of VNS to reduce seizure frequency and, consequently, to improve efficiency and savings in medical resources, which would then become either unnecessary or reduced. Yet this only applies to those cases in which there is total or partial control of seizures and an eventual improvement overall. This outcome occurs in only a portion of implanted patients. Notwithstanding the current study, evidence suggests that, when compared with VNS implants, epilepsy surgeries have consistently shown better results in terms of seizure control. Thus, the costs and benefits should be carefully considered when this particular method is indicated.

The Brazilian League of Epilepsy, here represented by its Committee of Neuromodulation, as well as the Brazilian Academy of Neurology, here represented by its Scientific Department of Epilepsy, are medical societies responsible for monitoring epilepsy (including both training and medical/ general education and evaluating the potential diagnostic and therapeutic resources). They are in agreement that tertiary-level epilepsy centers should determine whether VNS is indicated and should perform the implants. This would seem to be a reasonable approach, considering that VNS implantation represents an adjuvant technology, with an indication in patients whose clinical resistance is clearly established and in patients who are not considered good candidates for epilepsy surgery for many different reasons. Our current understanding of this degree of reliability can be defined only by trained and professional staff with access to all forms of diagnostic tools and surgical treatment of epilepsy, ensuring that the patient has access to the best possible care. Only with such rigor, together with narrow indication, can the cost and benefit ratio of VNS be properly estimated.

\section{References}

1. Duncan JS, Sander JW, Sisodiya SM, Walker MC. Adult epilepsy. Lancet 2006;367:1087-1100.

2. Sørensen AT, Kokaia M. Novel approaches to epilepsy treatment. Epilepsia 2013;54:1-10.

3. Rizzi M, Casazza M, Broggi G. Proceedings from the workshop on palliative epilepsy surgery: why, when, how? In Milano, Italy. World Neurosurg 2012

4. Kwan P, Arzimanoglou A, Berg AT, et al. Definition of drug resistant epilepsy: consensus proposal by the ad hoc Task Force of the ILAE Commission on Therapeutic Strategies. Epilepsia 2010;51:1069-1077.

5. Fauser S, Zentner J. Critical review of palliative surgical techniques for intractable epilepsy. Adv Tech Stand Neurosurg 2012;39:165-194.

6. Helmers SL, Duh MS, Guérin A, et al. Clinical outcomes, quality of life, and costs associated with implantation of vagus nerve stimulation therapy in pediatric patients with drug-resistant epilepsy. Eur $\mathrm{J}$ Paediatr Neurol 2012;16:449-458

7. Roberts DM, Siegel AM. Section of the corpus callosum for epilepsy. In Schmidek HH, Roberts DW (eds) Operative Neurosurgical Techniques: Indications, Methods and Results. Philadelphia: Saunders Elsevier, 2006:1413-1421.

8. Ping Z, Ji-Wen X, Gui-Song W, Hong-Yu Z, Xin T. Evaluation of efficacy and safety of anterior corpus callosotomy with keyhole in refractory seizures. Seizure 2009;18:417-419.

9. Al-Otaibi FA, Hamani C, Lozano AM. Neuromodulation in epilepsy. Neurosurgery 2011;69:957-979.

10. Zaaimi B, Héberlé C, Berquin P, Pruvost M, Grebe R, Wallois F. Vagus nerve stimulation induces concomitant respiratory alterations and a decrease in $\mathrm{SaO}_{2}$ in children. Epilepsia 2005;46:1802-1809.
11. Schachter SC, Saper CB. Vagus nerve stimulation. Epilepsia 1998;39:677-686.

12. Roosevelt RW, Smith DC, Clough RW, Jensen RA, Browning RA Increased extracellular concentrations of norepinephrine in cortex and hippocampus following vagus nerve stimulation in the rat. Brain Res 2006;1119:124-132.

13. Hassert DL, Miyashita T, Williams CL. The effects of peripheral vagal nerve stimulation at a memory-modulating intensity on norepinephrine output in the basolateral amygdala. Behav Neurosci 2004;118:79-88.

14. Hammond BM, Uthman BM, Wilder BJ, et al. Neurochemical effects of vagus nerve stimulation in humans. Brain Res 1992;583:300-303.

15. Narayanan JT, Watts R, Haddad N, Labar DR, Li PM, Philippi CG. Cerebral activation during vagus nerve stimulation. Epilepsia 2002;43:1509-1514.

16. Takaya M, Terry WJ, Naritoku DK. Vagus nerve stimulation induces a sustained anticonvulsant effect. Epilepsia 1996;37:1111-1116.

17. Henry TR, Votaw JR, Pennell PB, et al. Acute blood flow changes and efficacy of vagus nerve stimulation in partial epilepsy. Neurology 1999;52:1166-1173.

18. Kuba R, Guzaninová N, Brázdil M, NovákZ, Chrastina J, Rektor I. Effect of vagal nerve stimulation on interictal epileptiform discharges: a scalp EEG study. Epilepsia 2002;43:1181-1188.

19. Zabara J. Inhibition of experimental seizures in canines by repetitive vagal stimulation. Epilepsia 1992;33:1005-1012.

20. Zabara J. Controlling seizures by changing GABA receptor sensitivity. Epilepsia 1987;28:604.

21. Zabara J. Peripheral control of hypersynchronous discharge in epilepsy. Electroencephalogr Clin Neurophysiol 1985;61(Suppl):S162. 
22. WoodburyDM,WoodburyJW. Effects of vagal stimulation on experimentally induced seizures in rats. Epilepsia 1990;31(Suppl 2):S7-S19.

23. Woodbury JW, Woodbury DM. Vagal stimulation reduces the severity of maximal electroshock seizures in intact rats: use of a cuff electrode for stimulating and recording. PACE 1991;14:94-107.

24. Lockard JS, Congdon WC, DuCharme LL. Feasibility and safety of vagal stimulation in monkey model. Epilepsia 1990;3l(Suppl 2):S20-S26.

25. Ben-Menachem E, Mañon-Espaillat R, Ristanovic R, et al. Vagus nerve stimulation for treatment of partial seizures: 1. A controlled study of effect on seizures. Epilepsia 1994;35:616-626.

26. Morris GL 3rd, Mueller WM. Long-term treatment with vagus nerve stimulation in patients with refractory epilepsy. The vagus nerve stimulation study group E01-E05. Neurology 1999;53:1731-1735.

27. Ronkainen E, Korpelainen JT, Heikkinen E, Myllylä VV, Huikuri HV, Isojärvi JIT. Cardiac autonomic control in patients with refractory epilepsy before and during vagus nerve stimulation treatment: a oneyear follow-up study. Epilepsia 2006;47:556-562.

28. Harden CL, Pulver MC, Ravdin LD, Nikolov B, Halper JP, Labar DR. A pilot study of mood in epilepsy patients treated with vagus nerve stimulation. Epilepsy Behav 2000;1:93-99.

29. Nahas Z, Marangell LB, Husain MM, et al. Two-year outcome of vagus nerve stimulation (VNS) for treatment of major depressive episodes.J Clin Psychiatry 2005;66:1097-1104.

30. Nei M, O’Connor M, Liporace J, Sperling MR. Refractory generalized seizures: response to corpus callosotomy and vagal nerve stimulation. Epilepsia 2006;47:115-122.

31. Zaaimi B, Grebe R, Berquin B, Wallois F. Vagus nerve stimulation induces changes in respiratory sinus arrhythmia of epileptic children during sleep. Epilepsia 2009;50:2473-2480.
32. Labar D. Vagus nerve stimulation for 1 year in 269 patients on unchanged antiepileptic drugs. Seizure 2004;13:392-398.

33. Malow BA, Edwards J, Marzec M, et al. Effects of vagus nerve stimulation on respiration during sleep: a pilot study. Neurology 2000;55:1450-1454

34. Murphy JV. Left vagal nerve stimulation in children with medically refractory epilepsy. The Pediatric VNS Study Group. J Pediatr 1999;134:563-566.

35. Zaaimi B, Grebe R, Berquin P, Wallois F. Vagus nerve stimulation therapy induces changes in heart rate of children during sleep. Epilepsia 2007;48:923-930.

36. Terra VC, Nisyiama MA, Sakamoto AC, Machado HR. Vagus nerve stimulation in pediatric epilepsy patients: is this really worthwhile? Epilepsia 2012;53(Suppl 5):S223.

37. Kostov H, Larsson PG, Røste GK. Is vagus nerve stimulation a treatment option for patients with drug-resistant idiopathic generalized epilepsy?Acta Neurol Scand 2007;187(Suppl):S55-S58.

38. Ng M, Devinsky O. Vagus nerve stimulation for refractory idiopathic generalized epilepsy. Seizure 2004;13:176-178.

39. Smith B, Shatz R, Elisevich K, Bespalova IN, Burmeister M. Effects of vagus nerve stimulation on progressive myoclonus epilepsy of Unverricht-Lundborg type. Epilepsia 2000;41:1046-1048.

40. Englot DJ, Chang EF, Auguste KI. Vagus nerve stimulation for epilepsy: a meta-analysis of efficacy and predictors of response. J Neurosurg 2011;115:1248-1255.

41. Campagna-Gibson ML, Naritoku DK. Tolerability of rapid initiation and titration of vagus nerve stimulation (VNS). Epilepsia 2004;45(Suppl 7):S99. 